Document downloaded from:

http://hdl.handle.net/10251/50836

This paper must be cited as:

Cantó Perelló, J.; Curiel Esparza, J.; Calvo Peña, V. (2013). Criticality and threat analysis on utility tunnels for planning security policies of utilities in urban underground space. Expert Systems with Applications. 40(11):4707-4714. doi:10.1016/j.eswa.2013.02.031.

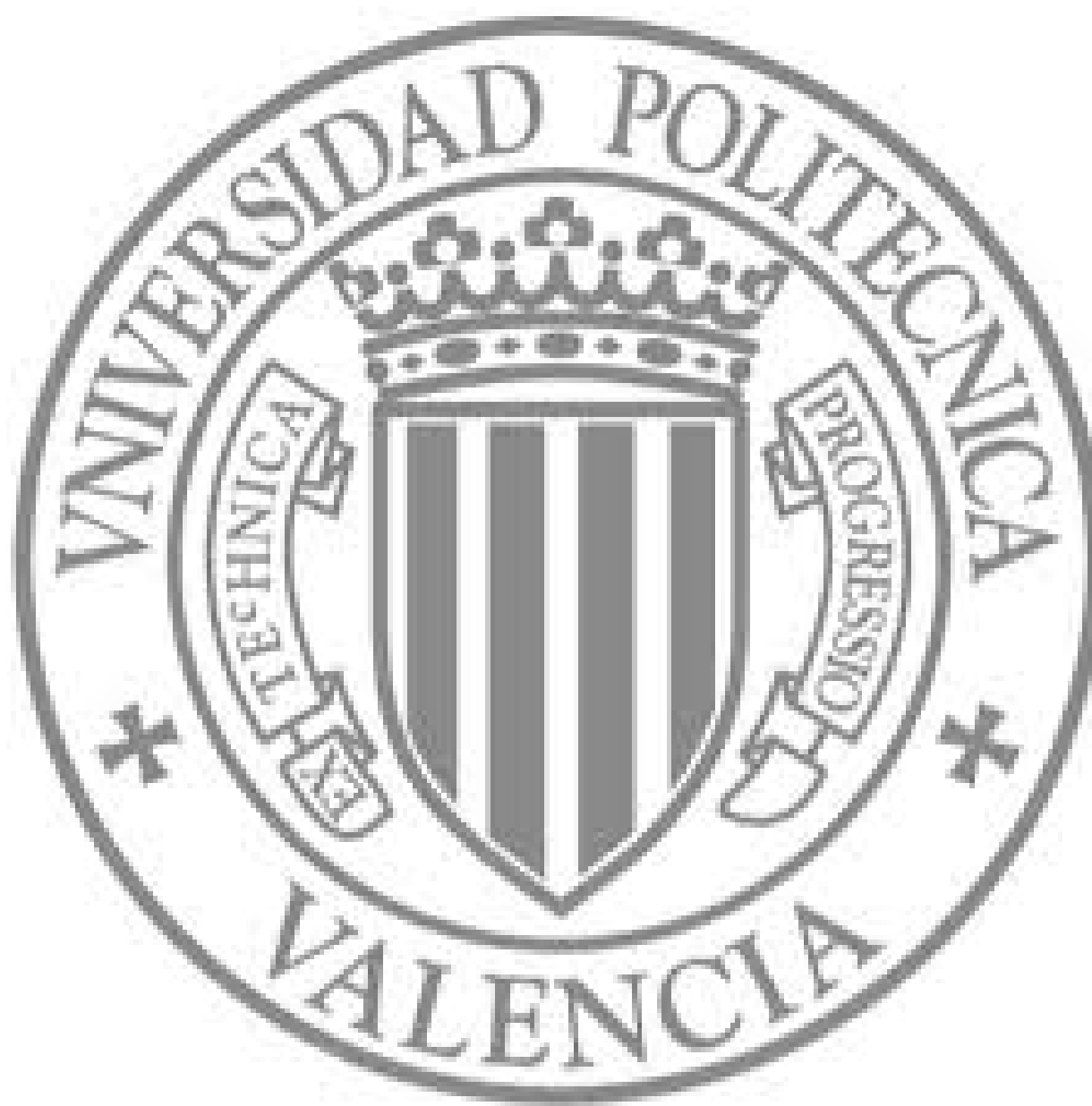

The final publication is available at

http://dx.doi.org/10.1016/j.eswa.2013.02.031

Copyright Elsevier 


\title{
Criticality and threat analysis on utility tunnels for planning security policies of utilities in urban underground space
}

\author{
Julian Canto-Perello ${ }^{a^{*}}$, Jorge Curiel-Esparza ${ }^{b}$ Vicente Calvo $^{c}$ \\ ${ }^{a}$ Department of Construction Engineering and Civil Engineering Projects, Universitat Politecnica \\ de Valencia, Valencia, Spain.

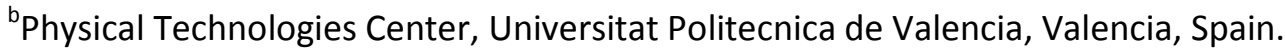 \\ ${ }^{c}$ Faculty of Industrial Engineering, Universitat Politecnica de Valencia, Valencia, Spain. \\ *Corresponding author: Universitat Politecnica de Valencia, Camino de Vera s/n 46022 \\ Valencia, Spain; Email: jcantope@cst.upv.es \\ Tel.: +34-96-387-7560; Fax: +34-96-387-7569.
}

\begin{abstract}
A utility tunnel is defined as an underground structure containing one or more utilities, permitting the installation, maintenance and removal of the systems without the necessity of making street cuts or excavations. These underground facilities contain all essential utilities serving large urban areas collected together in a tunnel; therefore they are an inviting target for sabotage or vandalism. This paper proposes an expert system combining color-coded scales, Delphi and AHP methods to analyze criticality and threats on utility tunnels to support planning of security policies for utilities in urban subsurface.
\end{abstract}

\section{Keywords}

Utilities security strategies; utility tunnels networks; urban underground space; color-coded scaled Delphi method; Analytic Hierarchy Process 


\section{Introduction}

Since the Second Industrial Revolution, rapid urban growth has created problems in finding underground space for the necessary pipes and cables of the assorted utilities. There is a virtual maze of utilities underground that have been added gradually and usually unsystematically over a long period of time. This maze of utilities has been ironically termed "the spaghetti subsurface problem" (Oude 1992) by municipal engineers. Because of the expanding population with its demands for more diversified services, we cannot afford this piecemeal type of utilities growth (Sterling \& Carmody, 1993; Sterling, 1997; Cano-Hurtado \& Canto-Perello, 1999; Duffaut \& Labbe, 2002; Zhang et al., 2009; He et al., 2012; Jung, 2012). Moreover, it is part of European Union policy to achieve a high level of health and environmental protection, and one of the objectives to be pursued is sustainable development (Steurera \& Bergerb, 2011). One solution appears to rest in the use of utility tunnels as a more sustainable technique (Canto-Perello \& Curiel-Esparza, 2006; Choon et al., 2011). Utility tunnels can house the full range of electric power, water, communications, heating lines, gas and other public services. They may well constitute the answer to the perennial problem plaguing many municipalities: how to accommodate needed utilities without the mutual interference caused by the operation and maintenance of these utilities and urban streets (Canto-Perello \& Curiel-Esparza, 2009; Rogers et al., 2012). Compartmentalization of subsurface public service systems largely follows historical development without considerations of the benefits of integration. Usually, companies were established to address specific utilities (electricity, telephone, gas, etc.) without considering sustainable integration. Placing utility networks in tunnels can avoid the continual cutting of pavements resulting from present trenching technique and should facilitate the installation, inspection, replacement, and maintenance of these facilities. In addition, utility tunnels enable an easy and inexpensive preventive and predictive maintenance to avoid utilities failures or leakages promoting a more efficient use of resources.

No serious technical problems with respect to utilities have been reported with the exception that sewers generally cannot be installed in tunnels unless grade and elevation conditions are coincident or pressure systems are utilized. In addition, considerable apprehension remains about the inclusion of gas systems in utility tunnels. However, previous studies relating to utility tunnels have evidenced concern by utility companies and others as to compatibility among utilities in a tunnel environment; the hazards of gas leaks and explosions; water pipe leaks and rupture; hazards to workmen from unfamiliar systems; as well as security issues (Canto-Perello \& Curiel-Esparza, 2003; Curiel-Esparza \& Canto-Perello, 2005, Abdul Salam, 2007; Zhou et al. 2009; Fouladgar et al., 2012; Ghorbani et al., 2012). The technical feasibility of the utility tunnel concept depends on the adequacy of the technology for the solution of problems expected to be encountered in the construction of utility tunnels, the installation of utility systems therein, and the operation and maintenance of the installed utilities (CurielEsparza et al., 2004). Nowadays, considerable attention has been given to utilities both from the point of view of the impact on the environment and the utilities security. 
Because of assembly of a large number of utility systems in a small space, the utility tunnel might be an inviting target for vandalism or sabotage. Hence, there is an increasing interest in security policies on utility tunnels, which has become a matter of great concern (Gilbert et al, 2003; Godard, 2004; Curiel-Esparza \& Canto-Perello, 2012). In addition, utility tunnels cannot afford high threat level for a long term without serious operational and economic consequences. Therefore, adequate security policies should be developed and maintained updated to protect citizens and utilities from potential threats without disrupting public services. For this reason, criticality and threats on utility tunnels should be analyzed in detail as an essential step in planning security strategies. Moreover, threat analysis is not limited only to extremist or criminal threats. For the purposes of this study, we will focus also on disgruntled employees and urban explorers. In this paper, we present an expert system for planning security policies of utilities based on color-coded scales, Delphi technique and Analytic Hierarchy Process (AHP) methodology. The Delphi method is an experts' foresight process about the likelihood that certain events will occur (Hsu \& Sandord, 2007; Ma et al., 2011; Marchais-Roubelat \& Roubelat, 2011). The AHP is a decision-making tool which can be used to solve complex foresight problems (Lee \& Chan, 2008; Syamsuddin \& Hwang, 2010; Feng et al. 2011; Joshi et al. 2011; Vidal et al. 2011; Zavadskas et al., 2011). It uses a multi-level hierarchical structure of criteria and alternatives. The pertinent data are derived by using a set of pairwise comparisons matrices. These comparisons are used to obtain the criticality, and the relative priority of the possible threats in terms of each impact on the community. If the comparisons are not consistent, then it provides a mechanism for noticing the inconsistency of the experts' judgments.

\section{Hierarchy structure for critically and threat analysis}

Arranging the threats and impacts in a hierarchy structure serves to two objectives. First, it shows an overall view of the complex issues found in any security analysis. And second, helps to compare criteria accurately. In order to evaluate priorities, it is required that the threats and impacts been compared must be gradually layered in the hierarchy, so that it is meaningful to compare them among themselves in relation to the element of the upper level (Saaty, 1990). Since resources are limited, this method for ranking criticality and threats will be useful in establishing priorities for implementing security infrastructure and programs. The security threats from which utility tunnels need to be protected must be identified for each local case, considering both internal and external threats (Lemley et al., 2003; Seger, 2003; Li et al., 2009; Caponecchia, 2012; Canto-Perello \& Curiel-Esparza, 2013). Obviously, threats may be originated from more than one group, with different methods and purposes. In general, at least the following threats are present:

- Disgruntled employees (DE). Dismissed or mistreated employees are unpredictable in terms of the behavior as each person reacts to work pressures differently. 
- White collar and common criminals (CC). These criminals use the tunnels to steal information from the telecommunication networks or to access other neighboring facilities and buildings that are its final targets.

- Terrorists (TE). Utility tunnels might be their target itself or as a mean to access other facilities or buildings like before.

- Violent activists (AC). Their acts are aimed to disrupt public services to make visible their arguments and obtain political gain through their actions.

- Vandals (VA). Producing damage to utility tunnel's systems such as ransacking, graffiti, placing glue into locks and so on.

- Urban explorers (UX). They are groups of people known as urbex who actively enjoy exploring underground infrastructures and sharing their photographs in internet. The rule of urban exploring "take nothing but photographs, leave nothing but footprints" may appear without malice, but because of placing information about access to tunnels on anonymous websites, it would be relatively easy for a terrorist or saboteur to enter a utility tunnel.

There are several different criteria that can be evaluated when determining criticality in underground facilities. Obviously, criticality and threats should be tailored to each particular case. For instance, in utility tunnels' networks, the following criteria should be evaluated:

- Impact on national infrastructure (INI).

- Impact on local infrastructure (ILI).

- Impact on community population (ICP).

- Impact on utility tunnel employees (ITE).

- Environmental impact (ENI).

- Local business impact (LBI).

Considering the impacts and threats exposed above, and following the initial step of AHP methodology (Ozdemir \& Saaty, 2006; Saaty, 2008; Thapa \& Murayama, 2010), the analysis is decomposed into a multi-level hierarchy structure shown in Fig. 1 . The next step in the AHP is the estimation of the pertinent data, to this end, a Delphi technique with a color-coded scale will be performed. This color scale makes clever use of familiar colors to exploit experts' opinion, subsequently transformed into numerical values. These data are then evaluated by using a set of pairwise comparisons matrices. Afterwards, these comparisons are used to obtain the weights of each criticality factor, and the relative importance of the threats in terms of each criterion. The quality of the output of the AHP is related to the consistency of the 
pairwise comparison judgments, and therefore it will be evaluated. Finally, the results from the analysis will be used to design administrative and physical precautions required to prevent entry by unauthorized persons, television monitoring networks, sensing devices and other security systems. As in similar cases (Canto-Perello \& Curiel-Esparza, 2001; Tang et al., 2009), the cost of integrating security measures during the project phase of any facility is far lower than adopting them once it has been constructed.

\section{Color-coded Delphi method for experts' decision process}

Color-coded scales used on risks and safety assessment have been developed by a large number of organizations (ANSI, 2011). For example, the American Public Works Association (APWA) encourages public agencies and private companies involved in underground engineering to adopt APWA Uniform Color Code for utility location (APWA, 1999). This marking code provides rules for the temporary marking of subsurface facilities to prevent accidents and damage or service interruption by contractors, excavators, utility companies, municipalities or any others working on or near underground facilities. In the United States, the Department of Homeland Security used a five color-coded threat advisory scale (low = green; guarded = blue; elevated = yellow; high $=$ orange; severe $=$ red) to provide an effective procedure to manage information regarding risks (HSPD3, 2002). In addition, during the 1970's, Regnier proposed a technique of consulting experts in strategic foresight by means of a colored voting ballot, known as Regnier's Abacus which is still in use (Regnier, 1975; Regnier, 1989; Godet et al., 2006; Godet \& Durance, 2011). Therefore, color-coded scales have been used in public works, security and strategic assessment. The basic idea will be to seek the opinions of experts using a color scale which ranges from green to red.

The object of the Delphi method is to obtain a reliable foresight from a panel of experts. The process guides the experts towards a consensus (Mullins, 2006; Chow \& Sadler, 2010; Gracht, 2012). It is important to study the opinions of experts from different fields. In our case, a panel size of ten experts has been used. After selection of experts' panel, the first round questionnaire is undertaken (see Table 1 ) to analyze criticality on utility tunnels. In a Delphi study, the experts do not interact with one another, and responses to questionnaires are anonymous. For evaluation of experts' opinion, the color scale is performed to make concrete and workable individual expressions. The use of color scale removes anxiety of decision making and helps creative thinking. The results of each round of questionnaires are transmitted to the panelists. The experts are allowed to adjust their answers in order to obtain a feedback from them in subsequent rounds. Several methods are available in AHP for performing the aggregation including the geometric mean method and arithmetic mean method (Ramanathan, 2001). In our case, the arithmetic mean method will be used to construct pairwise comparison matrices from experts' judgments. Performing the same procedure as before, a second questionnaire to assess main threats is developed (see Table 2). 


\section{Criticality assessment of impacts using pairwise comparison matrices}

The color-coded scale Delphi process has achieved interaction among the panel of experts with anonymous feedback, while AHP will be used to divide the overall foresight into smaller components. As AHP needs numerical values to construct the pairwise comparisons matrices, color-coded terms must be translated to an AHP 9-point scale evaluating intensity of criticality as shown in Table 3. This scale has been validated for effectiveness, not only in many applications by a number of people, but also through theoretical comparisons with a large number of other scales (Saaty, 1990). As a result, a matrix evaluating criticality for each expert is obtained from Table 1 . Then, the pairwise comparison matrix for criticality $(A)$ is constructed using the mean value obtained from experts. The matrix is given by

$$
A=\left[\begin{array}{cccccc}
1 & 0.640 & 0.162 & 0.217 & 0.653 & 0.221 \\
1.563 & 1 & 0.217 & 0.573 & 2.067 & 0.867 \\
6.177 & 4.605 & 1 & 2.133 & 6.600 & 2.133 \\
4.605 & 1.744 & 0.469 & 1 & 4.520 & 2.133 \\
1.531 & 0.484 & 0.152 & 0.221 & 1 & 0.240 \\
4.526 & 1.154 & 0.469 & 0.469 & 4.167 & 1
\end{array}\right]
$$

AHP is supported on the research of the physiologist George Miller (Miller, 1956), who stated that humans cannot deal with decisions involving simultaneously seven plus or minus two facts, because they become confused and cannot handle the data. This is in harmony with the stability of the principal eigenvalue to small perturbations when the order of the matrix $(n)$ is small and its central role in the measurement of consistency. The relative criticality of each individual impact will be determined performing the eigenvector method with its corresponding consistency analysis. That is, the principal eigenvector of $A$ is the desired criticality vector $w$ according to Saaty (1980). To find this criticality vector, the linear system $A \omega=\lambda \omega$ must be solved

$$
\operatorname{det}(A-\lambda I)=0
$$

Therefore, the criticality vector is as follows

$$
\omega=\left[\begin{array}{l}
0.0494 \\
0.1071 \\
0.3896 \\
0.2325 \\
0.0540 \\
0.1675
\end{array}\right]
$$

The Saaty's method measures the inconsistency of the pairwise comparison matrix and sets a consistency threshold which should not be exceeded in order to guarantee the procedure. 
That is, experts are often not able to express consistent preferences in multiple choice foresights. To address this, the consistency ratio $(C R)$ is evaluated as the main indicator of ranking consistency. In practice, a $C R$ of 0.1 or below is considered acceptable for order of matrix ( $n$ ) equal or larger than five. Any higher value indicates that the foresights need reexamination. $C R$ is obtained by dividing the consistency index $(C l)$ by the random consistency index (RCI) addressed by Saaty (1980), as follows

$$
C R=\frac{C l}{R C l}
$$

The largest eigenvalue $\left(\lambda_{\max }\right)$ of the normalized pairwise comparison matrix $\left(A_{N}\right)$ should be evaluated to obtain the $(C l)$. The normalized matrix $A_{N}$ is as follows

$$
A_{N}=\left[\begin{array}{llllll}
0.052 & 0.067 & 0.066 & 0.047 & 0.034 & 0.034 \\
0.081 & 0.104 & 0.088 & 0.124 & 0.109 & 0.131 \\
0.318 & 0.478 & 0.405 & 0.462 & 0.347 & 0.324 \\
0.237 & 0.181 & 0.190 & 0.217 & 0.238 & 0.324 \\
0.079 & 0.050 & 0.061 & 0.048 & 0.053 & 0.036 \\
0.233 & 0.120 & 0.190 & 0.102 & 0.219 & 0.152
\end{array}\right]
$$

Hence, the consistency index $(C l)$ is determined as follows

$$
C l=\frac{\lambda_{\max }-n}{n-1}
$$

Table 4 shows the criticality rating and consistency assessment performed. If the consistency ratio of an individual matrix or the entire hierarchy is found to be unacceptable, the experts' judgments must be reviewed. In addition, judgments and results cannot be extrapolated to any other case, because all the data are empirical and provided by experts' panel ad hoc. Moreover, any significant alterations of the existing utility tunnel network would necessitate another assessment by the experts' panel.

\section{Developing ratings for threats using pairwise comparison matrices}

The following step is to evaluate how important are threats with respect to each impact. To this end, the second questionnaire which was sent to the experts will be evaluated. As an example, Table 2 shows one of the questionnaires for evaluating threats with respect to an individual impact (INI-Impact on National Infrastructure) to better illustrate the use of the proposed procedure. Each expert has performed a pairwise comparison to indicate his preference for each threat, and then converted to an AHP scale using Table 5. Later, a pairwise comparison matrix for the threats is constructed using the mean value obtained from experts. As in the previous section, eigenvector method has been applied to obtain the priority vector, 
and consistency analysis performed for each case. Results of all threats assessments for each impact are shown in Table 6 to Table 11. The last step is to calculate the overall rating of threats. First, a matrix of threats importance vectors for each impact is constructed as shown in Table 12. And finally, the overall rating (see Table 13) is obtained by matrix multiplication between the threats vs. impact matrix and the criticality vector.

Obviously, results will vary depending on the case being studied. As an example, the criticality of each impact is shown in Fig. 2, while the weights of each threat for each impact are illustrated in Fig. 3. In our case, terrorists (32,28\%), violent activist $(22,18 \%)$ and disgruntled employees $(20,72 \%)$ are the main threats for the panel of experts. Each utility tunnel network should develop its own specific threat analysis, and the security provisions of utility tunnels must be planned using these results. For example, limiting the number of entrances and exits for personnel and material, together with appropriate locked doors in direct entry from buildings served by lateral tunnels are usually suitable countermeasures for urban explorers and vandals. While plus strict sign-in and sign-out procedures are adequate for threats from disgruntled employees. Protective lighting to discourage unauthorized entry will be suited for vandals and violent activist. Closed circuit TV, surveillance and alarm systems might reduce the vulnerability against terrorist, common criminals and vandals. The characteristics and number of the security personnel required will also depend on the type of threats forecasted. Finally, the authority responsible for the utility tunnel system should carefully control the dissemination of its threat study that might be useful to an adversary.

\section{Conclusions}

Motivations for utility tunnel installations are quite varied although the principal motivation has been to eliminate the ever increasing utility cuts which cause great expense and significant interference to urban environment. These facilities are undoubtedly an inviting target for sabotage or vandalism, as they contain all essential utilities serving large urban areas. Therefore, when utility tunnels are projected and managed, it is very important to plan their utilities security policies adequately. To achieve this goal consistently, the criticality and possible threats must be analyzed in detail. The proposed expert system, based on Delphi Color-Coded Scaled and AHP, provides support in decision-making for the systematic planning of security policies for utilities. Finally, some limitations of our procedure should be noted and discussed. First, the applied procedure is intended for the entire network of utility tunnels. And second, if there is any particular section near to a critical infrastructure or building, a special study should be performed and ad hoc measures undertaken.

\section{References}

Abdul Salam, A.O. (2007). Safety in automated transportation tunnels. In 15th Mediterranean Conference on Control and Automation, Athens, Greece. 
ANSI Z535.1-2006 - R2011. (2011) Safety colors. American National Standards Institute, Inc.

APWA (American Public Works Association) (1999). Color Code and Marking Guidelines, 4/1999.

Ben-Haim, Y. (2012). Doing our best: optimization and the management of risk. Risk Analysis, 32 (8), 1326-1332.

Cano-Hurtado, J.J., \& Canto-Perello, J. (1999). Sustainable development of urban underground space for utilities. Tunnelling and Underground Space Technology, 14 (3), 335-340.

Canto-Perello, J., \& Curiel-Esparza, J. (2001). Human factors engineering in utility tunnel design. Tunnelling and Underground Space Technology, 16 (3), 211-215.

Canto-Perello, J., \& Curiel-Esparza, J. (2003). Risks and potential hazards in utility tunnels for urban areas. Proceedings of the Institution of Civil Engineers-Municipal Engineer, 156 (1), 51 56.

Canto-Perello, J., \& Curiel-Esparza, J. (2006). An analysis of utility tunnel viability in urban areas. Civil Engineering and Environmental Systems, 23 (1), 11-19.

Canto-Perello, J., \& Curiel Esparza, J. (2013). Assessing governance issues of urban utility tunnels. Tunnelling and Underground Space Technology, 33 (1), 82-87.

Canto-Perello, J., Curiel-Esparza, J., \& Calvo, V. (2009). Analysing utility tunnels and highway networks coordination dilemma. Tunnelling and Underground Space Technology, 24 (2), 185189.

Caponecchia, C. (2012). Relative risk perception for terrorism: implications for preparedness and risk communication. Risk Analysis, 32 (9), 1524-1534.

Choon, S.W., Siwara, C., Pereira, J.J., Jemainc, A.A., Hashima, H.S., \& Hadib, A.S. (2011). A sustainable city index for Malaysia. International Journal of Sustainable Development \& World Ecology, 18 (1), 28-35.

Chow, T.E., \& Sadler, R. (2010). The consensus of local stakeholders and outside experts in suitability modelling for future camp development. Landscape and Urban Planning, 94 (1), 919.

Curiel-Esparza, J., \& Canto-Perello, J. (2005). Indoor atmosphere hazard identification in person entry urban utility tunnels. Tunnelling and Underground Space Technology, 20 (5), 426-434.

Curiel-Esparza, J., \& Canto-Perello, J., 2012. Understanding the major drivers for implementation of municipal sustainable policies in underground space. International Journal of Sustainable Development \& World Ecology, 19 (6), 506-514.

Curiel-Esparza, J., Canto-Perello, J., \& Calvo, M.A., 2004. Establishing sustainable strategies in urban underground engineering. Science and Engineering Ethics, 10 (3), 523-530. 
Duffaut, P., \& Labbe, M. (2002). From underground road traffic to underground city planning, in Proceedings of the International Conference Urban Underground Space: a Resource for Cities, Torino, Italy.

Feng, B., Ma, J., \& Fan Z.P. (2011). An integrated method for collaborative R\&D project selection: supporting innovative research teams. Expert Systems with Applications, 38 (5), 5532-5543.

Fouladgar, M.M., Yazdani-Chamzini, A., \& Zavadskas, E.K. (2012). Risk evaluation of tunnelling projects. Archives of Civil and Mechanical Engineering, 12 (1), 1-12.

Ghorbani, M., Sharifzadeh, M., Yasrobi, S., \& Daiyan, M. (2012). Geotechnical, structural and geodetic measurements for conventional tunnelling hazards in urban areas - The case of Niayesh road tunnel project. Tunnelling and Underground Space Technology, 31 (1), 1-8.

Gilbert, P.H., Isenberg, J., Baecher, G.B., Papay, L.T., Spielvogel, L.G., Woodard, J.B., \& Badolato, E.V. (2003). Infrastructure issues for cities - countering terrorist threat. Journal of Infrastructure Systems, 9 (1), 44-54.

Godard, J.P. (2004). Urban underground space and benefits of going underground. In Proceedings of the World Tunnel Congress of the International Tunnelling Association, Singapore.

Godet, M., \& Durance, P. (2011). La prospective stratégique, pour les entreprises et les territoires. Paris, UNESCO-Dunod

Godet, M., Durance, P., \& Gerber, A. (2006). Strategic foresight, la prospective problems and methods. Paris, Laboratoire d'Investigation en Prospective, Stratégie et Organisation.

Gracht, H.A. (2012). Consensus measurement in Delphi studies, review and implications for future quality assurance. Technological Forecasting and Social Change, 79 (8), 1525-1536.

He, L., Song, Y., Dai, S., \& Durbak, K. (2012). Quantitative research on the capacity of urban underground space - The case of Shanghai, China. Tunnelling and Underground Space Technology, 32 (1), 168-179.

HSPD3 (Homeland Security Presidential Directive 3). (2002). Homeland Security Advisory System. Washington.

Hsu, C.C., \& Sandord, B.A. (2007). The Delphi technique: making sense of consensus. Practical Assessment. Research and Evaluationm 12(10), 1-7.

Joshi, R., Banwet, D.K., \& Shankar, R. A Delphi-AHP-TOPSIS based benchmarking framework for performance improvement of a cold chain. Expert Systems with Applications, 38 (8), 1017010182.

Jung, Y.J. (2012). Evaluation of subsurface utility engineering for highway projects: Benefitcost analysis. Tunnelling and Underground Space Technology, 27 (1), 111-122. 
Lee, G.K.L., \& Chan, E.H.W. (2008). The analytic hierarchy process (AHP) approach for assessment of urban renewal proposals. Social Indicators Research, 89 (1), 155-168.

Lemley, J.R., Fthenakis, V.M., \& Moskowitz, P.D. (2003). Security risk analysis for chemical process facilities. Process Safety Progress, 22(3), 153-162.

Li, H., Apostolakis G.E., Gifun J., VanSchalkwyk, W, Leite, S., \& Barber, D. (2009). Ranking the risks from multiple hazards in a small community. Risk Analysis 29 (3), 438-456.

Ma, Z., Shao, C., Ma, S., \& Ye, Z. (2011). Constructing road safety performance indicators using Fuzzy Delphi Method and Grey Delphi Method. Expert Systems with Applications, 38 (3), 15091514.

Marchais-Roubelat, A., \& Roubelat, F. (2011). The Delphi method as a ritual: inquiring the Delphi Oracle. Technological Forecasting \& Social Change, 78 (9), 1491-1499.

Miller, G.A. (1956). The magical number seven, plus or minus two: some limits on our capacity for processing information. The Psychological Review, 63 (1), 81-97.

Mullins, D. (2006). Exploring change in the housing association sector in England using the Delphi method. Housing Studies, 21 (2), 227-251.

Oude, E.H.I. (1992). Underground space for utilities. In International Conference on Underground Space and Earth Sheltered Structures, Delft, Holland.

Ozdemir, M.S., \& Saaty, T.L. (2006). The unknown in decision making, what to do about it. European Journal of Operational Research, 174 (1), 349-359.

Ramanathan, R. (2001). A note on the use of the analityc hierarchy process for environmental impact assessment. Journal of Environmental Management, 63 (1), 27-35.

Regnier, F. (1975). Utilisation de l'Abaque coloré comme outil d'une logique de la communication et de la découverte. Strasbourg: Université Louis Pasteur, Séminaire sur le Fondement des Sciences, Fundamenta Scientiae.

Régnier, F. (1989). Annoncer la color. Nancy: Institut de metrólogie qualitative.

Rogers, C.D.F., Hao, T., Costello, S.B., Burrow, M.P.N., Metje, N., Chapman, D.N., Parker, J., Armitage, R.J., Anspach, J.H., Muggleton, J.M., Foo, K.Y., Wang, P., Pennock, S.R., Atkins, P.R., Swingler, S.G., Cohn, A.G., Goddard, K., Lewin, P.L., Orlando, G., Redfern, M.A., Royal, A.C.D., \& Saul, A.J. (2012). Condition assessment of the surface and buried infrastructure - A proposal for integration. Tunnelling and Underground Space Technology, 28 (1), 202-211.

Saaty, T.L. (1980). The analytic hierarchy process. New York: McGraw-Hill.

Saaty, T.L. (1990). How to make a decision: the analytic hierarchy process. European Journal of Operational Research, 48 (1), 9-26.

Saaty, T.L. (2008). Decision making with the analytic hierarchy process. International Journal of Services Sciences, 1 (1), 83-98. 
Seger, K.A. (2003). Utility security: the new paradigm. Tulsa: PennWell Corporation.

Sterling, R. (1997). Underground technologies for livable cities. Tunnelling and Underground Space Technology, 12 (4), 479-490.

Sterling, R., \& Carmody, J. (1993). Underground Space Design, New York: Van Nostrand Reinhold.

Steurera, R., \& Bergerb, G. (2011). The EU's double-track pursuit of sustainable development in the 2000s: how Lisbon and sustainable development strategies ran past each other. International Journal of Sustainable Development \& World Ecology, 18 (2), 99-108.

Syamsuddin, I., \& Hwang, J., 2010. The use of AHP in security policy decision making: an open office calc application. Journal of Software, 5 (10), 1162-1169.

Tang, A.-P., Li, Z.-Q., Feng, R.-C., \& Zhou, X.-Y. (2009). Model experiment and analysis on seismic response of utility tunnel systems using a shaking table. Journal of Harbin Institute of Technology, 41 (6), 1-5.

Thapa, R.B., \& Murayama, Y. (2010). Drivers of urban growth in the Kathmandu valley, Nepal: examining the efficacy of the analytic hierarchy process. Applied Geography, 30 (1), 70-83.

Viddal, L.A., Marle, F., \& Bocquet, J.C. (2011). Using a Delphi process and the Analitic Hierarchy Process (AHP) to evaluate the complexity of projects. Experts Systems with Applications, 38 (5), 5388-5405.

Zavadskas, E.K., Turskis, Z., \& Tamosaitiene, J. (2011). Selection of construction enterprises management strategy based on SWOT and multi-criteria analysis. Archives of Civil and Mechanical Engineering, 11 (4), 1063-1082.

Zhang, J.C., Ding, X.M., Pang, Y.S., Li, W.P., Tong, H.W., Zheng, X.C., \& Xu, Y. (2009). Analysis for development and utilization of underground space in Guangzhou. Gongcheng Lixue Engineering Mechanics, 26 (2), 106-114.

Zhou, J., Tang, Q., \& Zhang, J. (2009). Dynamic risk assessment for excavation engineering based on human factors. In 1st International Conference on Information Science and Engineering, Nanjing, China. 


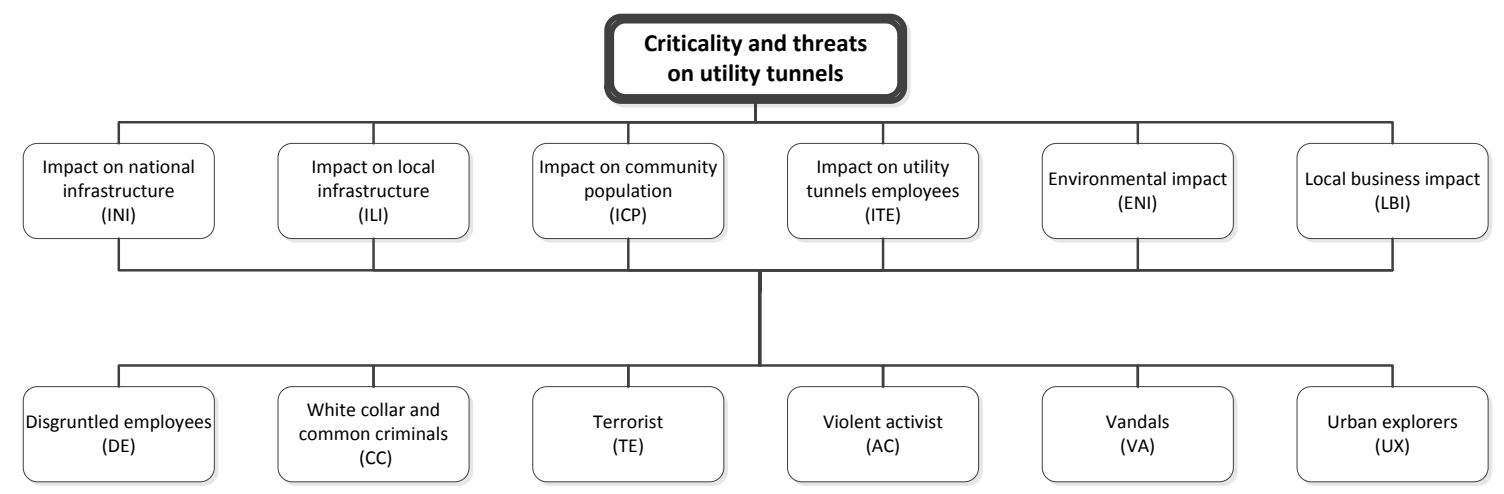

Fig. 1. Hierarchy structure to determine criticality and threats on utility tunnels in urban underground

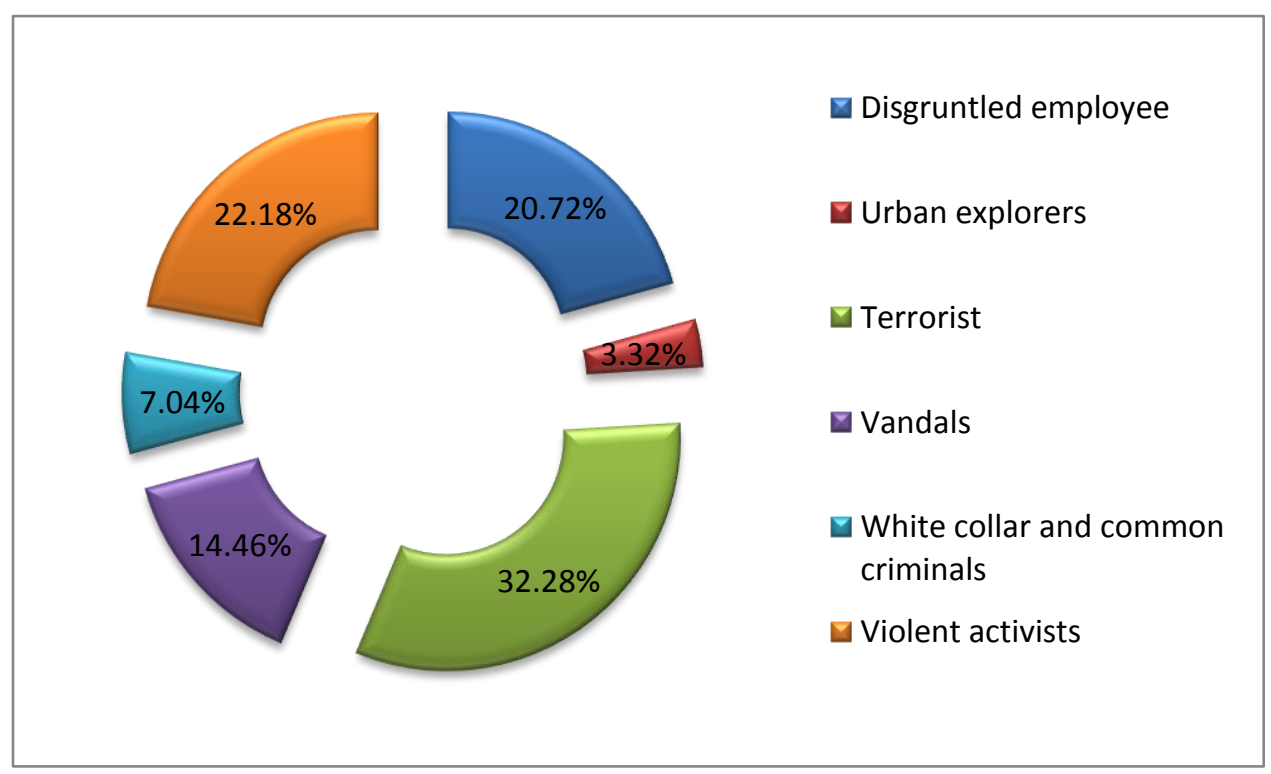

Fig. 2. Criticality of each threat on the utility tunnels analyzed. 


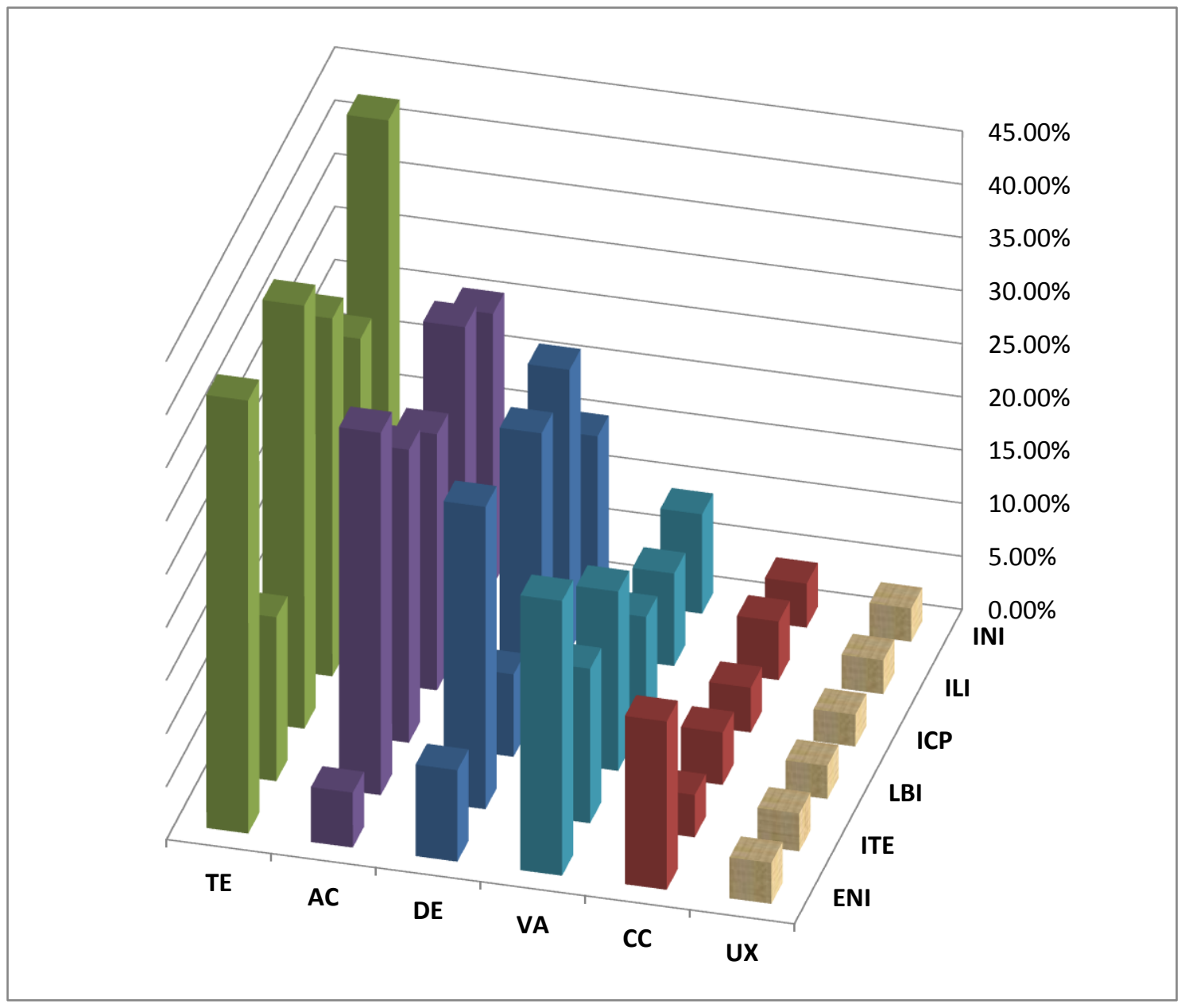

Fig. 3. The weights of each threat for each impact. 
Analysis of criticality on utility tunnels in urban areas

Q1 How critical are utility tunnels with respect to impact on national infrastructure (INI) vs. impact on local infrastructure (ILI)?

More

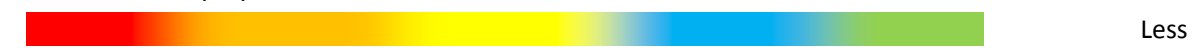

Q2 How critical are utility tunnels with respect to impact on national infrastructure (INI) vs. impact on community population (ICP)?

More Less

Q3 How critical are utility tunnels with respect to impact on national infrastructure (INI) vs. impact on utility tunnels employees (ITE)?

More Less

Q4 How critical are utility tunnels with respect to impact on national infrastructure (INI) vs. environmental impact (ENI)?

More Less

Q5 How critical are utility tunnels with respect to impact on national infrastructure (INI) vs. local business impact (LBI)?

More

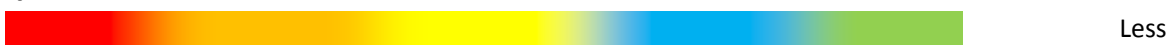

Q6 How critical are utility tunnels with respect to impact on local infrastructure (ILI) vs. impact on community population (ICP)?

More

$$
\text { population (ICP)? }
$$

Less

Q7 How critical are utility tunnels with respect to impact on local infrastructure (ILI) vs. impact on utility tunnels employees (ITE)?

More Less

Q8 How critical are utility tunnels with respect to impact on local infrastructure (ILI) vs. environmental impact (ENI)?

More Less

Q9 How critical are utility tunnels with respect to impact on local infrastructure (ILI) vs. local business impact (LBI)?

More Less

Q10 How critical are utility tunnels with respect to impact on community population (ICP) vs. impact on utility tunnels employees (ITE)?

More Less

Q11 How critical are utility tunnels with respect to impact on community population (ICP) vs. environmental impact (ENI)?

More Less

Q12 How critical are utility tunnels with respect to impact on community population (ICP) vs. local business impact (LBI)?

More Less

Q13 How critical are utility tunnels with respect to impact on utility tunnels employees (ITE) vs. environmental impact (ENI)?

More Less

Q14 How critical are utility tunnels with respect to impact on utility tunnels employees (ITE) vs. local business impact (LBI)?

More Less

Q15 How critical are utility tunnels with respect to environmental impact (ENI) vs. local business impact (LBI)?

More Less

Table 1 . First round questionnaire to assess criticality on utility tunnels. 


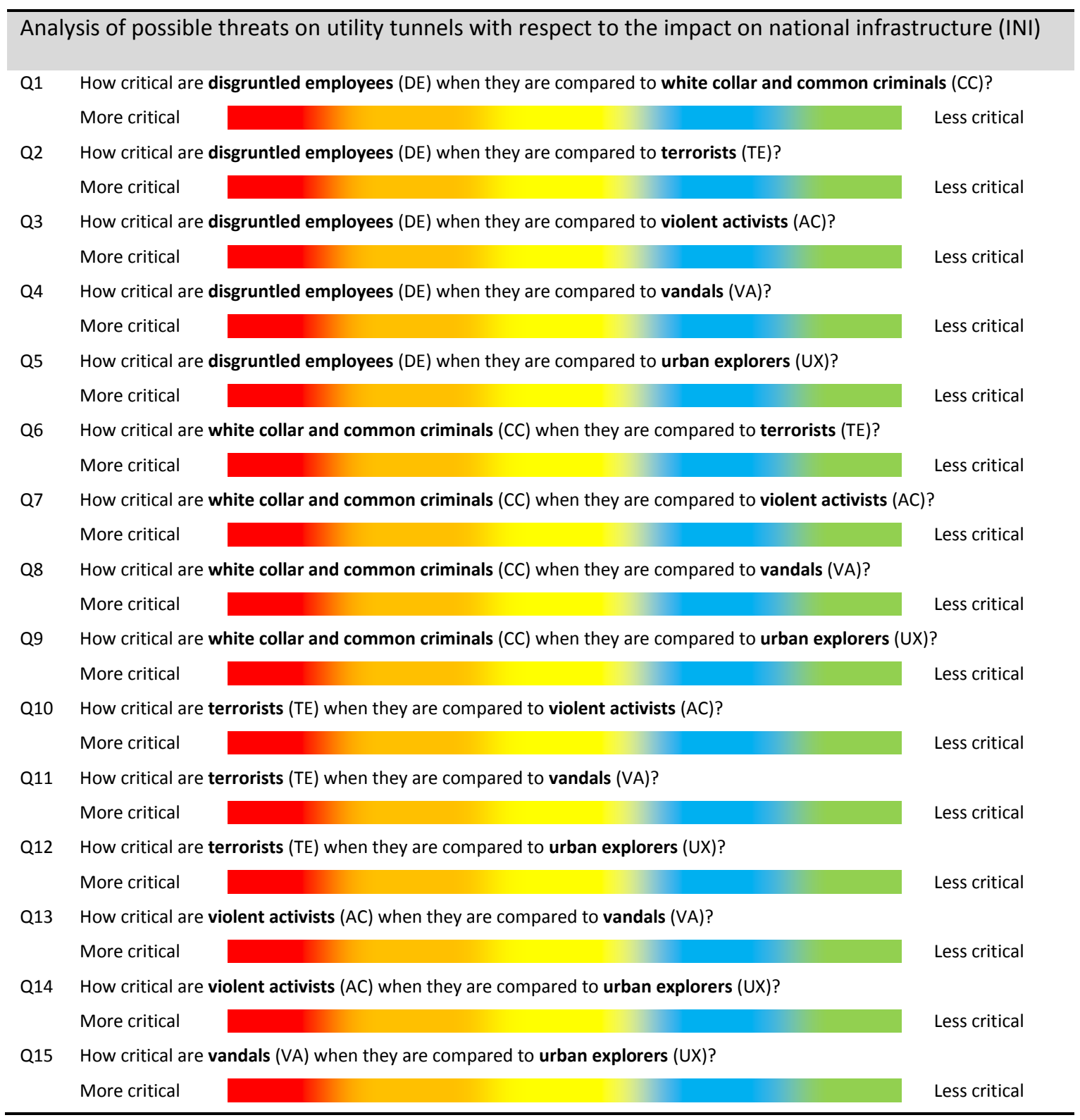

Table 2 . Second round questionnaire to assess main threats on utility tunnels.

\begin{tabular}{llc}
\hline Color-coded scale & \multicolumn{1}{c}{ Meaning } & Intensity of criticality \\
\hline & An impact is extremely critical to another & 9 \\
& An impact is very strongly critical to another & 7 \\
& An impact is moderately critical to another & 5 \\
& An impact is slightly critical to another & 3 \\
& An impact is equally critical to another & 1 \\
& An impact is slightly non-critical to another & $1 / 3$ \\
An impact is moderately non-critical to another & $1 / 5$ \\
An impact is very strongly non-critical to another & $1 / 7$ \\
An impact is extremely non-critical to another & $1 / 9$ \\
\hline
\end{tabular}

Table 3. 9-point AHP scale to evaluate intensity of criticality from color-coded scale. 


\begin{tabular}{|c|c|c|c|c|c|c|c|}
\hline & INI & ILI & ICP & ITE & ENI & LBI & Criticality Vector \\
\hline INI & 1 & 0.640 & 0.162 & 0.217 & 0.653 & 0.221 & 0.049 \\
\hline ILI & 1.563 & 1 & 0.217 & 0.573 & 2.067 & 0.867 & 0.107 \\
\hline ICP & 6.177 & 4.605 & 1 & 2.133 & 6.600 & 2.133 & 0.390 \\
\hline ITE & 4.605 & 1.744 & 0.469 & 1 & 4.520 & 2.133 & 0.233 \\
\hline ENI & 1.531 & 0.484 & 0.153 & 0.221 & 1 & 0.240 & 0.054 \\
\hline LBI & 4.526 & 1.154 & 0.469 & 0.469 & 4.167 & 1 & 0.168 \\
\hline
\end{tabular}

Table 4. Criticality vector and consistency assessment of the pairwise comparison matrix.

\begin{tabular}{llc}
\hline Color-coded scale & \multicolumn{1}{c}{ Meaning } & Intensity of threats \\
\hline & A threat is extremely critical to another & 9 \\
A threat is very strongly critical to another & 7 \\
A threat is moderately critical to another & 5 \\
A threat is slightly critical to another & 3 \\
A threat is equally critical to another & 1 \\
A threat is slightly non-critical to another & $1 / 3$ \\
A threat is moderately non-critical to another & $1 / 5$ \\
A threat is very strongly non-critical to another & $1 / 7$ \\
A threat is extremely non-critical to another & $1 / 9$ \\
\hline
\end{tabular}

Table 5. 9-point AHP scale to evaluate intensity of threats from color-coded scale.

\begin{tabular}{|c|c|c|c|c|c|c|c|}
\hline INI & $\overline{D E}$ & $\mathrm{CC}$ & TE & $\mathrm{AC}$ & VA & UX & Criticality Vector \\
\hline DE & 1 & 3.800 & 0.267 & 0.667 & 1.733 & 6.400 & 0.154 \\
\hline CC & 0.263 & 1 & 0.133 & 0.160 & 0.280 & 1.667 & 0.041 \\
\hline TE & 3.750 & 7.500 & 1 & 2.133 & 5.600 & 8.400 & 0.425 \\
\hline AC & 1.500 & 6.250 & 0.469 & 1 & 4.800 & 6.400 & 0.256 \\
\hline VA & 0.577 & 3.571 & 0.179 & 0.208 & 1 & 3.933 & 0.094 \\
\hline UX & 0.156 & 0.600 & 0.119 & 0.156 & 0.254 & 1 & 0.031 \\
\hline
\end{tabular}

Table 6. Criticality vector and consistency analysis of the pairwise comparison matrix for the threats with respect to impact on national infrastructure (INI). 


\begin{tabular}{|c|c|c|c|c|c|c|c|}
\hline ILI & DE & CC & TE & $A C$ & VA & UX & Criticality Vector \\
\hline $\mathrm{DE}$ & 1,0000 & 4,8000 & 0,8667 & 1,0667 & 3,9333 & 7,2000 & 0,2655 \\
\hline CC & 0,2083 & 1,0000 & 0,2667 & 0,1543 & 0,5333 & 2,1333 & 0,0551 \\
\hline TE & 1,1538 & 3,7500 & 1,0000 & 1,6000 & 2,2667 & 6,8000 & 0,2683 \\
\hline AC & 0,9375 & 6,4815 & 0,6250 & 1,0000 & 5,8000 & 7,6000 & 0,2924 \\
\hline VA & 0,2542 & 1,8750 & 0,4412 & 0,1724 & 1,0000 & 3,5333 & 0,0870 \\
\hline UX & 0,1389 & 0,4688 & 0,1471 & 0,1316 & 0,2830 & 1,0000 & 0,0318 \\
\hline
\end{tabular}

Table 7. Criticality vector and consistency analysis of the pairwise comparison matrix for the threats with respect to impact on local infrastructure (ILI).

\begin{tabular}{cccccccc}
\hline ICP & DE & CC & TE & AC & VA & UX & Criticality Vector \\
\hline DE & 1 & 5.800 & 0.933 & 1.187 & 3.333 & 6.400 & $\mathbf{0 . 2 5 5}$ \\
CC & 0.172 & 1 & 0.142 & 0.152 & 0.307 & 2.200 & $\mathbf{0 . 0 4 2}$ \\
TE & 1.071 & 7.031 & 1 & 3.000 & 2.933 & 7.200 & $\mathbf{0 . 3 3 7}$ \\
AC & 0.843 & 6.646 & 0.333 & 1 & 4.600 & 7.800 & $\mathbf{0 . 2 4 1}$ \\
VA & 0.300 & 3.261 & 0.341 & 0.217 & 1 & 4.200 & $\mathbf{0 . 0 9 5}$ \\
UX & 0.156 & 0.455 & 0.139 & 0.128 & 0.238 & 1 & $\mathbf{0 . 0 3 0}$ \\
\hline \multicolumn{7}{c}{$\lambda_{\max }=6,312$} & $\mathrm{Cl}=0.063$
\end{tabular}

Table 8. Criticality vector and consistency analysis of the pairwise comparison matrix for the threats with respect to impact on community population (ICP).

\begin{tabular}{cccccccc}
\hline ITE & DE & CC & TE & AC & VA & UX & Criticality Vector \\
\hline DE & 1 & 0.733 & 0.217 & 2.200 & 0.227 & 1.733 & $\mathbf{0 . 0 8 6}$ \\
CC & 1.364 & 1 & 0.280 & 4.400 & 0.667 & 4.800 & $\mathbf{0 . 1 5 8}$ \\
TE & 4.605 & 3.571 & 1 & 7.200 & 1.800 & 7.800 & $\mathbf{0 . 4 0 7}$ \\
AC & 0.445 & 0.227 & 0.139 & 1 & 0.253 & 1.800 & $\mathbf{0 . 0 5 2}$ \\
VA & 4.412 & 1.500 & 0.556 & 3.947 & 1 & 7.400 & $\mathbf{0 . 2 5 8}$ \\
UX & 0.577 & 0.208 & 0.128 & 0.556 & 0.135 & 1 & $\mathbf{0 . 0 3 9}$ \\
\hline \multicolumn{7}{c}{$\lambda_{\max }=6,155$} & $\mathrm{Cl}=0.031$
\end{tabular}

Table 9. Criticality vector and consistency analysis of the pairwise comparison matrix for the threats with respect to impact on utility tunnels employees (ITE). 


\begin{tabular}{cccccccc}
\hline ENI & DE & CC & TE & AC & VA & UX & Criticality Vector \\
\hline DE & 1 & 1.933 & 0.185 & 0.183 & 0.320 & 4.133 & $\mathbf{0 . 0 7 8}$ \\
CC & 0.517 & 1 & 0.151 & 0.174 & 0.267 & 2.000 & $\mathbf{0 . 0 4 9}$ \\
TE & 5.412 & 6.618 & 1 & 2.000 & 3.000 & 8.400 & $\mathbf{0 . 3 9 8}$ \\
AC & 5.469 & 5.748 & 0.500 & 1 & 1.733 & 7.400 & $\mathbf{0 . 2 7 6}$ \\
VA & 3.125 & 3.750 & 0.333 & 0.577 & 1 & 5.000 & $\mathbf{0 . 1 6 9}$ \\
UX & 0.242 & 0.500 & 0.119 & 0.135 & 0.200 & 1 & $\mathbf{0 . 0 3 1}$ \\
\hline \multicolumn{7}{c}{$\lambda_{\max }=6.191$} & $\mathrm{Cl}=0.038$
\end{tabular}

Table 10. Criticality vector and consistency analysis of the pairwise comparison matrix for the threats with respect to environmental impact (ENI).

\begin{tabular}{cccccccc}
\hline LBI & DE & CC & TE & AC & VA & UX & Criticality Vector \\
\hline DE & 1 & 5.200 & 1.533 & 0.653 & 4.000 & 7.200 & $\mathbf{0 . 2 8 4}$ \\
CC & 0.192 & 1 & 0.301 & 0.139 & 0.148 & 1.133 & $\mathbf{0 . 0 4 0}$ \\
TE & 0.652 & 3.323 & 1 & 0.667 & 0.800 & 4.333 & $\mathbf{0 . 1 5 4}$ \\
AC & 1.531 & 7.192 & 1.500 & 1 & 3.933 & 7.800 & $\mathbf{0 . 3 4 1}$ \\
VA & 0.250 & 6.760 & 1.250 & 0.254 & 1 & 4.200 & $\mathbf{0 . 1 4 5}$ \\
UX & 0.139 & 0.882 & 0.231 & 0.128 & 0.238 & 1 & $\mathbf{0 . 0 3 6}$ \\
\hline \multicolumn{7}{c}{$\lambda_{\max }=6.296$} & $\mathrm{Cl}=0.059$
\end{tabular}

Table 11. Criticality vector and consistency analysis of the pairwise comparison matrix for the threats with respect to impact on local business impact (LBI).

\begin{tabular}{ccccccc}
\hline & INI & ILI & ICP & ITE & ENI & LBI \\
\hline DE & 0.154 & 0.266 & 0.255 & 0.086 & 0.078 & 0.284 \\
CC & 0.041 & 0.055 & 0.042 & 0.158 & 0.049 & 0.040 \\
TE & 0.425 & 0.268 & 0.337 & 0.407 & 0.398 & 0.154 \\
AC & 0.256 & 0.292 & 0.241 & 0.052 & 0.276 & 0.341 \\
VA & 0.094 & 0.087 & 0.095 & 0.258 & 0.169 & 0.145 \\
UX & 0.031 & 0.032 & 0.030 & 0.039 & 0.031 & 0.036 \\
\hline
\end{tabular}

Table 12. Threats vs. impacts matrix. 


\begin{tabular}{lc}
\hline \multicolumn{1}{c}{ Threat } & Overall rating \\
\hline DE - Disgruntled employee & 0.207 \\
CC - Common criminals & 0.070 \\
TE - Terrorist & 0.323 \\
AC - Violent activists & 0.222 \\
VA - Vandals & 0.145 \\
UX - Urban explorers & 0.033 \\
\hline
\end{tabular}

Table 13. Overall rating of threats. 